\title{
A shining star of congenital heart surgery-a tribute to Dr. William I Norwood Jr (1941-2020)
}

\author{
Smruti Ranjan Mohanty ${ }^{1}$
}

Received: 24 December 2020 / Revised: 7 January 2021 / Accepted: 12 January 2021 / Published online: 1 March 2021

(C) Indian Association of Cardiovascular-Thoracic Surgeons 2021

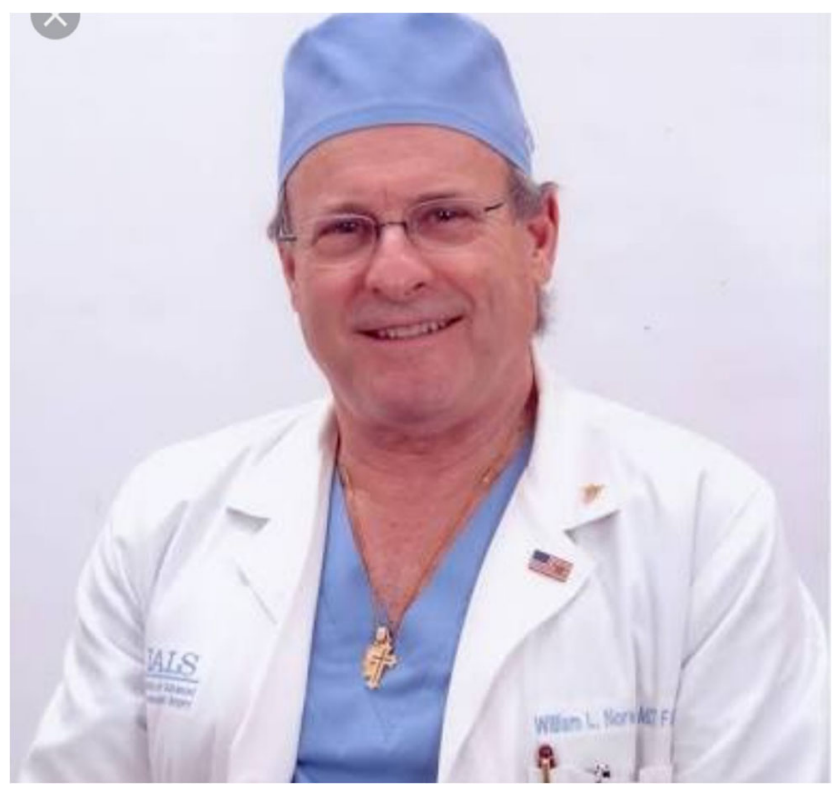

Over the last eight decades that congenital heart surgery has evolved as a specialty, Dr. William I Norwood Jr stands out for his groundbreaking contributions to its unparalleled progress.

After 2 years as a trainee fighter pilot at the Air Force Academy, he began his medical training in Colorado followed by surgical residency in Minnesota, working under giants like Varco and Lillehei. After a $\mathrm{PhD}$ in Biophysics, he did his cardiac surgery training at Harvard Medical School and subsequently joined the

Smruti Ranjan Mohanty

smrutiranjanmohanty699@gmail.com

1 Children's Heart Center, Kokilaben Dhirubhai Ambani Hospital, Four Bunglows, Andheri (West), Mumbai 400053, India
Children's Hospital in Boston as a faculty under Castenada. He left his mark at Children's Hospital of Philadelphia as the chief of the program for a decade. He briefly rejoined his mentor Dr. Aldo Castenada at his institute in Switzerland, before eventually concluding his stellar career at Nemours Cardiac Center, DE, where he set up a specialist center for the care of hypoplastic left heart syndrome (HLHS) babies.

When we interacted on the sidelines of a medical conference in Florida in 2010, I was awed by the ingeniousness of his ideas as he passionately described how he came up with one of the most brilliant techniques in the field of congenital heart surgery. He hypothesized 3 principles about HLHS based on which he pursued the staged surgical palliation he conceived.

First, the heart develops from days 19 to 58 in a growing fetus, after which it only grows in size and matures till term. He believed that if the heart in HLHS can support the circulation in fetal life till birth, it has the potential to support the circulation, provided appropriate surgical modifications are done at the right time.

Secondly, the right ventricle (RV) in HLHS is different than that of a normal biventricular heart, in terms of geometry of myocardial fiber arrangement, architecture of atrioventricular (AV) and outflow valves, and density and distribution of coronary arterial system, and thus is more suitable to sustain the systemic circulation.

Thirdly, if the first stage of surgical palliation is done appropriately, and in time with preservation of the RV function, the next two stages will be much less challenging.

Like all cardiac surgeons, he was extremely diligent, spending hours in the operating theater trying to perfectly reconstruct the neo aorta and arch from a noodle-size aorta and dilated main pulmonary artery, followed by establishing the pulmonary circulation with a Blalock-Taussig shunt ensuring that the systemic and pulmonary circulations were perfectly balanced. Such was his dedication that he stayed for days together with the HLHS babies postoperatively, in the 
intensive care unit, to give them the extra special care they needed.

The concept of the 3-stage surgical repair for babies with HLHS that he envisioned soon became reality and thousands of children around the world have undergone the Norwood procedure followed by bidirectional Glenn repair and finally the Fontan procedure. Thanks to his tireless efforts in perfecting this technique, countless children, who were doomed to the "compassionate care" pathway, overlooked by everyone else, were given a fresh lease of life and a fighting chance of survival to lead a nearly normal life well into adulthood.

He ventured with all his heart and mind into the uncharted territory of HLHS and strived to improve the "Norwood procedure" even till his last days. He was a shining star in our specialty and will always be a guiding light in the sky he used to fly high in. Even though he is no more, his incredible legacy will be eternal.

\section{Compliance with ethical standards}

Conflict of interest The author declares that he has no conflict of interest.

Ethical approval Not applicable.

Informed consent Not applicable.

Publisher's note Springer Nature remains neutral with regard to jurisdictional claims in published maps and institutional affiliations. 